\title{
Role of Ultrasonography and Magnetic Resonance Imaging (MRI) in Evaluation of the Tendons of the Wrist and Hand
}

\author{
WALEED A. MOUSA, M.D.*; MOHAMED S. EL-ZAWAWI, M.D.* and DINA M. BARSEEM, M.Sc.** \\ The Department of Radiodiagnosis, Faculty of Medicine* and National Liver Institute**, Menoufia University, Egypt
}

\begin{abstract}
Background: Variable abnormalities of the tendons of the wrist and hand including injury, inflammation, tumors \& anatomical variants used to be evaluated with MRI as a standard modality. Owing to MRI relative limited availability and its high cost, ultrasonography (US) considered a valuable tool in assessment of wrist and hand tendons.

Aim of Study: To assess the ultrasonography (US) results in comparison with MRI results which is used as gold standard in assessment of variable wrist and hand tendon abnormalities.

Patients and Methods: One hundred patients with different wrist and hand complaints were enrolled in our study, 43 females and 57 males their age between 8-82 years with a median age 45 years. All patients were subjected to history taking and full clinical examination of the wrist and hand. Each patient underwent the ultrasound first before the MRI examination.
\end{abstract}

Results: Near equal results were observed between US findings and MRI findings indicating that we can use both examinations to evaluate the wrist and hand tendons, and that US can be used as initial tool in assessment of the wrist and hand tendon abnormalities. According to our study, sonography exhibited $99 \%$ diagnostic accuracy for ganglion cysts, 100\% for solid masses of tendon sheath \& tendinosis/tenosynovitis, $97 \%$ for tendon injury \& $98 \%$ for anatomical variants of the wrist and hand tendons.

Conclusion: Our study demonstrated that ultrasonography and MRI are comparable and closely related as regards detection of different pathological changes in hand and wrist tendons. Further studies are needed to confirm the findings in larger groups of patients and to evaluate the role of Ultrasonography (US) in assessment of the other structures of the wrist and hand.

Key Words: Wrist hand tendons - Ultrasonography - MRI.

\section{Introduction}

IN the diagnosis of musculoskeletal disorders, there are several applications where both ultrasound and magnetic resonance imaging (MRI) may be considered viable alternatives [1].

Correspondence to: Dr. Dina M. Barseem, E-Mail: hamza said 2000@yahoo.com
The advent of ultra-high-frequency sonography transducers has significantly improved our ability to image superficial structures. Therefore, ultrasonography now can be used to evaluate injuries of the wrist and hand tendons [2].

Dynamic examination allows better evaluation of the type and extension of the lesions. An anatomical course of the nerves and tendons can be depicted by ultrasound, thus offering valuable information on the exact location and type of possible lesions [3].

The evaluation of a tendon abnormality can be accomplished with both MRI and ultrasound. Of course there are intrinsic advantages and disadvantages to both imaging methods. One significant advantage of MRI is the ability to globally assess a joint, diagnosing tendon, ligament, cartilage, and bone abnormalities, As an alternative algorithm, sonography may be considered the first line of imaging for joint problems after radiography [1]

Ultrasound can examine the whole length of a tendon, from the forearm to the distal insertion site. Tendons have a typical fibrillar echotexture, which reflects their histological structure of longitudinally oriented bundles of collagen fibers; normal tendons are more echogenic than muscle [4].

The musculoskeletal ultrasonography (MSK US) is noninvasive and more readily available. US has also the advantage of providing real-time and dynamic information on patients [5]. That's why interest in high-resolution ultra-sonography (US) is increasing [6].

Ultrasonography allows for a sensitive detection of periarticular soft tissue involvement including tendon inflammation and damage. Ultrasonography is quick, easy to perform, and safe. Moreover, it allows dynamic multiplanar information that helps to make an accurate diagnosis and also guides 
interventional diagnostic and/or therapeutic procedures [7]

The aim of this study is to assess the diagnostic value of ultrasound in detecting variable tendon abnormalities of the wrist and hand as compared to MRI examination.

\section{Material and Methods}

\section{Material:}

This prospective comparative study was performed between March 2017 and December 2019, One hundred patients were enrolled in our study, 43 females and 57 males their age between 8-82 years with a median age 45 years. All patients were referred to the Radiology Department of Menoufia University Hospital \& National Liver Institute/ Menoufia University from the outpatient clinics of Menoufia University for full investigation including X-ray, ultrasonography \& MRI examination.

\section{Inclusion criteria:}

Patients included in our study:

1- All patient complaining of the hand and wrist were included (pain, swelling, etc.).

2- No age group or gender predilection.

\section{Exclusion criteria:}

1- Patients with previous history of hand \& wrist surgery.

2- Contraindication to perform MRI examination. These included cardiac pacemaker, metallic aneurysm clips and cochlear implants.

\section{Ethical considerations:}

In the current study ethical considerations were explained to all the participants. The radiological investigations represent standard care and pose no ethical conflicts. All the patients gave oral consent to join in this study, which was accepted by the Local Institute of Ethical Committee of Menoufia University.

We subject all patients to the followings:

1- History taking: Including patient's name, age, and clinical presentation.

2- Full clinical examination of the hand and wrist.

\section{Methods:}

\section{Musculoskeletal Ultrasonography (MSK US):}

The patients were examined using Philips epiq7 ultrasound machine using a near focused linear array transducer with a center frequency of 7.5-12 MHz. It was equipped with a color/power Doppler.

The patient's hand was comfortably rested on a pillow placed over his thighs. Gel was applied over the wrist to give appropriate contact between the probe and skin and to smooth the uneven surface of the wrist. Dynamic examination with active flexion/extension of the fingers was done in all cases.

For the wrist: Dorsal longitudinal scan followed by dorsal transverse scan were done followed by palmar \& dorsal examination in supination \& pronation to evaluate flexor \& extensor tendons compartments, presence of soft tissue swelling \& presence of anatomical variant (palmaris longus variant, extensor digitorum manus, proximal insertion of lumbricals $\&$ accessory abductor digiti minimi).

For the hand:Dorsal/palmar longitudinal scan, lateral longitudinal scan and Dorsal/palmar transverse scan.

Grey-scale imaging evaluation confirms the presence or absence of (tendon tear, tenosynovitis, cyst or tumor related to tendons), Color Doppler was used to evaluate the presence of vascularity.

Interpretation of US findings: Images were analyzed by the operating experienced radiologist.

\section{MRI examination:}

Patients were examined by high field strength (1.5 T MRI system) [Toshiba Excelart Vantage, Japan] using flex surface coil with the patient in the prone position with arms up (superman position).

\section{Imaging acquisition protocol:}

- Localizer.

- Non contrast sequences/series (precontrast):

- Coronal and axial fast spin-echo T1-weighted (TR/TE, 400/15).

- Coronal and axial fast spin-echo T2-weighted (TR/ TE, 2000/70).

- Coronal, axial and sagittal proton density fat sat (TR/TE, 4000/35) sequences.

- A small field of view (8 to $10 \mathrm{~cm}$ ) was used. Slice thickness was $2.5 \mathrm{~mm}$ with $2 \mathrm{~mm}$ interslice gap.

- Contrast-enhanced sequences/series:

In case of presence of mass Contrast is given to evaluate the pattern of its enhancement.

A bolus of contrast (gadolinium-diethylene tri amino penta-acetic acid; Gd-DTPA), (Magnavist, Schering AG Berlin, Germany) was injected manually intravenous at a dose of $0.1 \mathrm{mmol}$ per kilogram body weight $(0.1 \mathrm{mmol} / \mathrm{kg})$ followed by saline flush. 
Coronal, sagittal and axial T1-weighted post contrast sequences are obtained.

Interpretation of the MRI findings was evaluated through two experienced radiologists, independently and if there is any disagreement, the case was discussed, and final decision was taken.

Image analysis: Ultrasound and MRI images were evaluated for the following features; tendon anatomical variants which include (accessory abductor digiti minimi, palmaris longus variants, proximal origin of the lumbricals \& Extensor Digitorum Brevis Manus), ganglion cyst of tendon sheath, solid masses of tendons (giant cell tumor), tendon inflammation and lastly tendon injury which include partial thickness, full thickness tendon tear $\&$ tendon subluxation.

\section{Statistical methods:}

Data were collected, tabulated, statistically analysed using an IBM personal computer with Statistical Package of Social Science (SPSS) version 22 (SPSS, Inc, Chicago, Illinois, USA). Where the following statistics was applied:

- Descriptive statistics: In which qualitative data were presented in the form numbers and percentages.

-Analytical statistics: Used to find out the possible association between studied factors and the targeted disease, the used tests of significance included, $p$-value of $<0.05$ was considered statistically significant.

\section{Results}

The study included one hundred patients complaining of different wrist and hand symptoms. 43 patients $(43 \%)$ were females, while 57 patients $(57 \%)$ were males, Age of the patient ranged from (8-82) years with median age 45 years. In our study, 50 patients showed painful wrist $(50 \%)$, other symptoms such as limitation of movement $(3 \%)$, and swellings (27\%), history of trauma was recorded in $20 \%$ of patients, whereas $80 \%$ were without history of trauma (Table 1).

Regarding anatomical variant of the wrist and hand tendons:

33 patients $(33 \%)$ had anatomical variants diagnosed by MRI while 31 patients $(31 \%)$ were diagnosed by ultrasound. The most common variant seen among the patients was accessory abductor digiti minimi muscle Fig. (1), 15 patients diagnosed by MRI while 13 patients diagnosed by ultrasound, second common variant was Palmaris Longus Variants (which include reversed insertion \& uni- lateral/bilateral agenesis) 13 patients diagnosed by both MRI \& ultrasound. Last two variants were not common which included proximal origin of the lumbricals \& Extensor Digitorum Brevis Manus, 3 patients diagnosed as proximal origin of the lumbricals by both MRI \& ultrasound while only 2 patients diagnosed as Extensor Digitorum Brevis Manus by both MRI \& ultrasound equally as shown in Tables $(2,3)$.

\section{Regarding ganglion cysts of tendon sheath:}

17 patients (17\%) had ganglion cyst of tendon sheath (Fig. 2) diagnosed by MRI while 16 patients $(16 \%)$ diagnosed by ultrasound as shown in Tables $(4,5)$.

\section{Regarding solid masses of tendon sheath:}

16 patients (16\%) had benign tumor of tendon sheath diagnosed with MRI with the same number of patients correctly diagnosed by ultrasound as shown in Tables $(6,7,8)$.

Benign tumor of tendon sheath includes giant cell tumor (Fig. 3) and fibroma, MRI could differentiate between both lesions using additional sequence Gradient echo sequence (GRE) which showed the Susceptibility artefacts seen in GCT due to presence of hemosiderin deposition while the fibroma has no Susceptibility artefacts. However the ultrasound could not differentiate between GCT and fibroma in our study.

\section{Regarding tendon injury:}

In our study tendons were assessed also for the integrity, thickness and echo pattern. Tendons injuries were classified into partial thickness tear, complete thickness tear, tendon subluxation \& pulley injury depending on their appearance.

The ultrasound could correctly diagnose tendon subluxation due to its dynamic property which showed radial or ulnar subluxation/dislocation of the tendons from its usual position.

24 patients (24\%) had tendon injuries diagnosed by MRI while 21 patients $(21 \%)$ were diagnosed by ultrasound (Tables 9,10 ).

Of the 24 patients diagnosed with MRI, there were eight patients with complete tears, nine patients with partial-thickness tears (Fig. 4), three patients with tendon subluxation without tear and four patients with pulley injury (Fig. 5).

Of the nine partial thickness tears confirmed by MRI, ultrasound correctly identified seven cases. In the misdiagnosed two cases, ultrasound described both as normal tendon, while a partial 
thickness tear was identified at MRI imaging. Of the eight patients MRI confirmed complete thickness tears; ultrasound correctly diagnosed seven patients, only one case was misdiagnosed as partial thickness tear.

Of the three tendon subluxation cases confirmed by MRI, ultrasound correctly diagnosed all the patients, again all four patients of pulley injury could be identified by ultrasound clearly.

\section{Regarding tendinosis/tenosynovitis:}

A total of 46 patients ( $46 \%$ ) diagnosed as tendinosis/tenosynovitis by MRI, with the same number of $46(46 \%)$ diagnosed by ultrasound, extensor compartments tendinosis/tenosynovitis (Fig. 6) was the most common finding (34 patients) followed by flexor tendinosis/tenosynovitis (eight patients) and stenosing tenosynovitis (trigger finger) (four patients) were the least common findings. (Tables 11,12).

The first extensor compartment tendons found to be the most common affected compartment among the studied group followed by the 6 th extensor compartment, while third \& fifth compartments were the least affected.

Trigger finger was diagnosed clearly by ultrasound as thickened A 1 pulley (diameter more than $1 \mathrm{~mm}$ ) at level of the metacarpal heads with alteration in the echopattern of the underlying flexor tendons that pass through the digital tunnel, MRI show similar finding regarding thickening of the A1 pulley.

\section{Regarding overall tendon abnormalities:}

By comparing with MRI diagnosis as reference standard, results of sonographic diagnosis among the studied group (one hundred patients) for all wrist and hand tendon abnormalities were shown in Tables $(13,14)$ respectively.

According to the diagnostic criteria defined in this study, sonography exhibited $99 \%$ for ganglion cysts, $100 \%$ for benign tumors of tendon sheath $\&$ tendinosis/tenosynovitis, $97 \%$ for tendon injury $\& 98 \%$ for anatomical variants. In the previous results showed that 16 ganglion cysts were correctly diagnosed on ultrasound with one false-negative.

With regard to tendon injury, there were 21 correctly diagnosed with only three false-negatives.

Regarding the anatomical variant of tendons of wrist \& hand, ultrasound could correctly diagnose 31 out of 33 MRI confirmed patients.
Table (1): Description of demographic data of patients and control groups.

\begin{tabular}{llc}
\hline Studied variables & No. & $\%$ \\
\hline Age / years & \multicolumn{2}{c}{$40.8 \pm 13.7$} \\
Mean \pm SD & \multicolumn{2}{c}{$8-82$} \\
Range & \multicolumn{2}{c}{} \\
Gender: & 57 & 57.0 \\
Male & 43 & 43.0 \\
Female & & \\
Complaint: & 50 & 50.0 \\
Pain & 27 & 27.0 \\
Swelling & 3 & 3.00 \\
Limitation of movement & 20 & 20.0 \\
$\quad$ Trauma & & \\
\hline
\end{tabular}

Table (2): Comparison between MRI and ultrasound in detection of anatomical variant of wrist and hand tendons.

\begin{tabular}{|c|c|c|c|c|c|c|}
\hline \multirow{2}{*}{ (Anatomical variant) } & \multicolumn{2}{|c|}{ MRI } & \multicolumn{2}{|c|}{ Ultrasound } & \multirow{2}{*}{$X^{2}$} & \multirow{2}{*}{$\begin{array}{c}p- \\
\text { value }\end{array}$} \\
\hline & No. & $\%$ & No. & $\%$ & & \\
\hline Positive: & 33 & 33.0 & 31 & 31.0 & 0.17 & 0.996 \\
\hline $\begin{array}{l}\text { - Accessory abductor } \\
\text { digiti minimi muscle }\end{array}$ & 15 & 15.0 & 13 & 13.0 & & \\
\hline $\begin{array}{l}\text { - Proximal Origin of } \\
\text { the Lumbricals }\end{array}$ & 3 & 3.00 & 3 & 3.0 & & \\
\hline $\begin{array}{l}\text { - Palmaris Longus } \\
\text { Variants }\end{array}$ & 13 & 13.0 & 13 & 13.0 & & \\
\hline $\begin{array}{l}\text { - Extensor Digitorum } \\
\text { Brevis Manus }\end{array}$ & 2 & 2.0 & 2 & 2.0 & & \\
\hline Negative & 67 & 67.0 & 69 & 69.0 & & \\
\hline
\end{tabular}

Table (3): Sensitivity and specificity of ultrasound compared to MRI as standard modality in detection of anatomical variant of wrist and hand tendons.

\begin{tabular}{lc}
\hline Ultrasound & Anatomical variant \\
\hline Sensitivity (\%) & $87 \%$ \\
Specificity (\%) & $100 \%$ \\
PPV (\%) & $100 \%$ \\
NPV (\%) & $98 \%$ \\
Accuracy (\%) & $98 \%$ \\
\hline
\end{tabular}

Table (4): Comparison between MRI and ultrasound in detection of ganglion cyst of tendon sheath.

\begin{tabular}{|c|c|c|c|c|c|c|}
\hline \multirow{2}{*}{$\begin{array}{l}\text { (Ganglion of } \\
\text { tendon sheath) }\end{array}$} & \multicolumn{2}{|c|}{ MRI } & \multicolumn{2}{|c|}{ Ultrasound } & \multirow{2}{*}{$X^{2}$} & \multirow{2}{*}{$\begin{array}{c}p- \\
\text { value }\end{array}$} \\
\hline & No. & $\%$ & No. & $\%$ & & \\
\hline Positive & 17 & 17.0 & 16 & 16.0 & 0.04 & 0.848 \\
\hline Negative & 83 & 83.0 & 84 & 84.0 & & \\
\hline
\end{tabular}


Table (5): Sensitivity and specificity of ultrasound in detection of ganglion cyst of tendon sheath.

\begin{tabular}{|c|c|c|c|c|}
\hline \multirow[b]{2}{*}{ Ultrasound } & \multicolumn{4}{|c|}{ Ganglion cyst of tendon sheath } \\
\hline & $\begin{array}{c}\text { True } \\
\text { positive } \\
\mathrm{N}(\%)\end{array}$ & $\begin{array}{c}\text { True } \\
\text { negative } \\
\mathrm{N}(\%)\end{array}$ & $\begin{array}{c}\text { False } \\
\text { Positive } \\
\text { N }(\%)\end{array}$ & $\begin{array}{c}\text { False } \\
\text { negative } \\
\mathrm{N}(\%)\end{array}$ \\
\hline & $16(16.0)$ & $83(83.0)$ & $0(0.00)$ & $1(1.00)$ \\
\hline Sensitivity (\%) & \multicolumn{4}{|c|}{$94 \%$} \\
\hline Specificity (\%) & \multicolumn{4}{|c|}{$100 \%$} \\
\hline PPV (\%) & \multicolumn{4}{|c|}{$99 \%$} \\
\hline NPV $(\%)$ & \multicolumn{4}{|c|}{$100 \%$} \\
\hline Accuracy $(\%)$ & \multicolumn{4}{|c|}{$99 \%$} \\
\hline
\end{tabular}

Table (6): Comparison between MRI and ultrasound in detection of solid tumors of tendon sheath.

\begin{tabular}{|c|c|c|c|c|c|c|}
\hline \multirow{2}{*}{$\begin{array}{l}\text { Solid tumor of } \\
\text { tendon sheath }\end{array}$} & \multicolumn{2}{|c|}{ MRI } & \multicolumn{2}{|c|}{ Ultrasound } & \multirow{2}{*}{$X^{2}$} & \multirow{2}{*}{$\begin{array}{c}p- \\
\text { value }\end{array}$} \\
\hline & No. & $\%$ & No. & $\%$ & & \\
\hline Positive & 16 & 16.0 & 16 & 16.0 & 0.00 & 1.00 \\
\hline Negative & 84 & 84.0 & 84 & 84.0 & & \\
\hline
\end{tabular}

Table (7): MRI differentiation of solid tumor of tendon sheath (GCT/Fibroma).

\begin{tabular}{lcccc}
\hline \multirow{2}{*}{$\begin{array}{l}\text { Solid tumor of } \\
\text { tendon sheath }\end{array}$} & \multicolumn{2}{c}{ MRI } & $\mathrm{X}^{2}$ & $\begin{array}{c}p \text { - } \\
\text { value }\end{array}$ \\
\cline { 2 - 3 } & No. & $\%$ & & \\
\hline Positive & 16 & 16.0 & 0.00 & 1.00 \\
Fibroma & 6 & 6.00 & & \\
Giant cell tumor & 10 & 10.0 & & \\
Negative & 84 & 84.0 & & \\
\hline
\end{tabular}

Table (8): Sensitivity and specificity of ultrasound in detection of Solid tumor of tendon sheath.

\begin{tabular}{|c|c|c|c|c|}
\hline \multirow[b]{2}{*}{ Ultrasound } & \multicolumn{4}{|c|}{ Solid tumor of tendon sheath } \\
\hline & $\begin{array}{c}\text { True } \\
\text { positive } \\
\mathrm{N}(\%)\end{array}$ & $\begin{array}{c}\text { True } \\
\text { negative } \\
\mathrm{N}(\%)\end{array}$ & $\begin{array}{c}\text { False } \\
\text { Positive } \\
\text { N }(\%)\end{array}$ & $\begin{array}{c}\text { False } \\
\text { negative } \\
\mathrm{N}(\%)\end{array}$ \\
\hline & $16(16.0)$ & $84(84.0)$ & $0(0.00)$ & $0(0.00)$ \\
\hline Sensitivity (\%) & \multicolumn{4}{|c|}{$100 \%$} \\
\hline Specificity $(\%)$ & \multicolumn{4}{|c|}{$100 \%$} \\
\hline PPV $(\%)$ & \multicolumn{4}{|c|}{$100 \%$} \\
\hline NPV $(\%)$ & \multicolumn{4}{|c|}{$100 \%$} \\
\hline Accuracy (\%) & \multicolumn{4}{|c|}{$100 \%$} \\
\hline
\end{tabular}

Table (9): Comparison between MRI and ultrasound in detection of tendon injury.

\begin{tabular}{|c|c|c|c|c|c|c|}
\hline \multirow{2}{*}{ Tendon injury } & \multicolumn{2}{|c|}{ MRI } & \multicolumn{2}{|c|}{ Ultrasound } & \multirow{2}{*}{$X^{2}$} & \multirow{2}{*}{$\begin{array}{c}p- \\
\text { value }\end{array}$} \\
\hline & No. & $\%$ & No. & $\%$ & & \\
\hline Positive & 24 & 24.0 & 21 & 21.0 & 0.01 & 0.914 \\
\hline $\begin{array}{l}\text { Partial thickness tear } \\
\text { of flexor tendon }\end{array}$ & 5 & 5.00 & 3 & 3.00 & & \\
\hline $\begin{array}{l}\text { Partial thickness tear } \\
\text { of extensor tendon }\end{array}$ & 4 & 4.00 & 4 & 4.00 & & \\
\hline $\begin{array}{l}\text { Complete thickness } \\
\text { tear of flexor tendon }\end{array}$ & 7 & 7.00 & 6 & 6.00 & & \\
\hline $\begin{array}{l}\text { Complete thickness } \\
\text { tear of extensor tendon }\end{array}$ & 1 & 1.00 & 1 & 1.00 & & \\
\hline Tendon subluxation & 3 & 3.00 & 3 & 3.00 & & \\
\hline Pulley injury & 4 & 4.00 & 4 & 4.00 & & \\
\hline Negative & 76 & 76.0 & 79 & 79.0 & & \\
\hline
\end{tabular}

Table (10): Sensitivity and specificity of ultrasound in detection of tendon injury.

\begin{tabular}{|c|c|c|c|c|}
\hline \multirow[b]{2}{*}{ Ultrasound } & \multicolumn{4}{|c|}{ Tendon tear } \\
\hline & $\begin{array}{c}\text { True } \\
\text { positive } \\
\mathrm{N}(\%)\end{array}$ & $\begin{array}{c}\text { True } \\
\text { negative } \\
\mathrm{N}(\%)\end{array}$ & $\begin{array}{c}\text { False } \\
\text { Positive } \\
\mathrm{N}(\%)\end{array}$ & $\begin{array}{c}\text { False } \\
\text { negative } \\
\mathrm{N}(\%)\end{array}$ \\
\hline & $21(21.0)$ & $76(76.0)$ & $0(0.00)$ & $3(3.00)$ \\
\hline Sensitivity (\%) & \multicolumn{4}{|c|}{$88 \%$} \\
\hline Specificity (\%) & \multicolumn{4}{|c|}{$100 \%$} \\
\hline PPV (\%) & \multicolumn{4}{|c|}{$100 \%$} \\
\hline NPV (\%) & \multicolumn{4}{|c|}{$96 \%$} \\
\hline Accuracy (\%) & \multicolumn{4}{|c|}{$97 \%$} \\
\hline
\end{tabular}

Table (11): Comparison between MRI and ultrasound in detection of tendinosis/tenosynovitis.

\begin{tabular}{|c|c|c|c|c|c|c|}
\hline \multirow{2}{*}{$\begin{array}{l}\text { (Tendinosis/ } \\
\text { tenosynovitis) }\end{array}$} & \multicolumn{2}{|c|}{ MRI } & \multicolumn{2}{|c|}{ Ultrasound } & \multirow{2}{*}{$X^{2}$} & \multirow{2}{*}{$\begin{array}{c}p- \\
\text { value }\end{array}$} \\
\hline & No. & $\%$ & No. & $\%$ & & \\
\hline Positive & 46 & 46.0 & 46 & 46.0 & 0.00 & 1.00 \\
\hline $\begin{array}{l}1^{\text {st }} \text { Extensor } \\
\text { compartment }\end{array}$ & 13 & 13.0 & 13 & 13.0 & & \\
\hline $\begin{array}{l}\text { 2nd Extensor } \\
\text { compartment }\end{array}$ & 4 & 4.0 & 4 & 4.0 & & \\
\hline $\begin{array}{l}\text { 3rd Extensor } \\
\text { compartment }\end{array}$ & 1 & 1.0 & 1 & 1.0 & & \\
\hline $\begin{array}{l}\text { 4th Extensor } \\
\text { compartment }\end{array}$ & 6 & 6.0 & 6 & 6.0 & & \\
\hline $\begin{array}{l}\text { 5th Extensor } \\
\text { compartment }\end{array}$ & 1 & 1.0 & 1 & 1.0 & & \\
\hline $\begin{array}{l}\text { 6th Extensor } \\
\text { compartment }\end{array}$ & 9 & 9.0 & 9 & 9.0 & & \\
\hline Flexor tenosynovitis & 8 & 8.0 & 8 & 8.0 & & \\
\hline Trigger finger & 4 & 4.0 & 4 & 4.0 & & \\
\hline Negative & 54 & 54.0 & 54 & 54.0 & & \\
\hline
\end{tabular}


Table (12): Sensitivity and specificity of ultrasound in detection of tendinosis/tenosynovitis.

\begin{tabular}{|c|c|c|c|c|c|c|c|c|c|}
\hline \multirow{4}{*}{ Ultrasound } & \multicolumn{4}{|c|}{ Tendinosis/tenosynovitis } & \multirow{3}{*}{ Tendon abnormalities } & \multirow{2}{*}{\multicolumn{2}{|c|}{ MRI }} & \multirow{2}{*}{\multicolumn{2}{|c|}{ Ultrasound }} \\
\hline & \multirow{3}{*}{$\begin{array}{c}\text { True } \\
\text { positive } \\
\mathrm{N}(\%)\end{array}$} & \multirow{3}{*}{$\begin{array}{c}\text { True } \\
\text { negative } \\
\mathrm{N}(\%)\end{array}$} & \multirow{3}{*}{$\begin{array}{c}\text { False } \\
\text { Positive } \\
\text { N (\%) }\end{array}$} & \multirow{3}{*}{$\begin{array}{c}\text { False } \\
\text { negative } \\
\mathrm{N}(\%)\end{array}$} & & & & & \\
\hline & & & & & & No. & $\%$ & No. & $\%$ \\
\hline & & & & & Positive & 87 & 87.0 & 82 & 82.0 \\
\hline & $46(46.0)$ & $54(54.0)$ & $0(0.00)$ & $0(0.00)$ & Ganglion cyst & 17 & 17.0 & 17 & 17.00 \\
\hline Sensitivity (\%) & & 10 & & & Solid tumors of tendon sheath & 16 & 16.0 & 16 & 16.00 \\
\hline Specificity (\%) & & 10 & & & Tendon injury & 24 & 24.0 & 21 & 21.00 \\
\hline PPV (\%) & & 10 & & & Tendinosis/tenosynovitis & 46 & 46.0 & 46 & 46.00 \\
\hline NPV (\%) & & 10 & & & Anatomical variants & 33 & 33.0 & 31 & 31.00 \\
\hline Accuracy (\%) & & 10 & & & Negative & 13 & 13.0 & 18 & 18.0 \\
\hline
\end{tabular}

Table (14): Sensitivity and specificity of ultrasound in detection of all tendon abnormalities of the wrist and hand.

\begin{tabular}{lcccc}
\hline \multirow{4}{*}{ Ultrasound } & \multicolumn{4}{c}{ All wrist abnormality } \\
\cline { 2 - 5 } & $\begin{array}{c}\text { True positive } \\
\text { N (\%) }\end{array}$ & $\begin{array}{c}\text { True negative } \\
\text { N (\%) }\end{array}$ & $\begin{array}{c}\text { False Positive } \\
\text { N (\%) }\end{array}$ & $\begin{array}{c}\text { False negative } \\
\text { N (\%) }\end{array}$ \\
\hline & $81(81.0)$ & $13(13.0)$ & $0(0.00)$ & $6(6.00)$ \\
Sensitivity (\%) & & $91 \%$ & \\
Specificity (\%) & & $100 \%$ & \\
PPV (\%) & & $100 \%$ & \\
NPV (\%) & & $68.4 \%$ & \\
Accuracy $(\%)$ & & $94 \%$ & \\
\hline
\end{tabular}

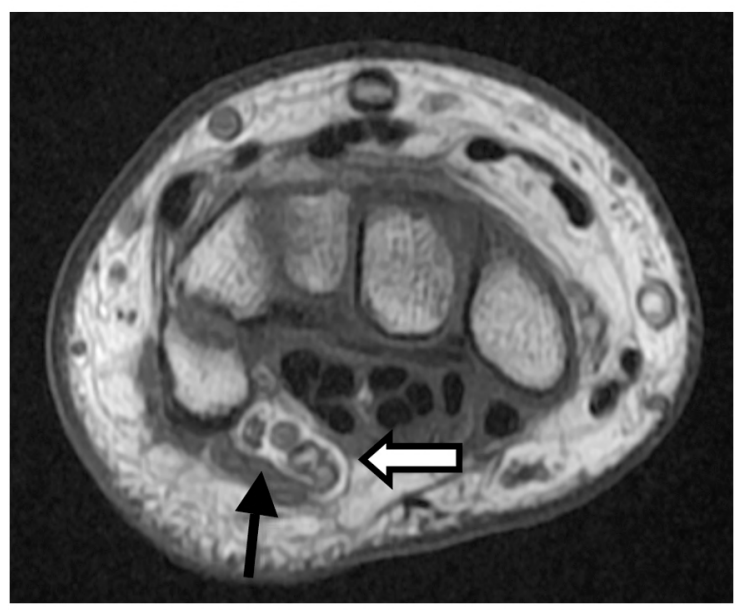

(A)

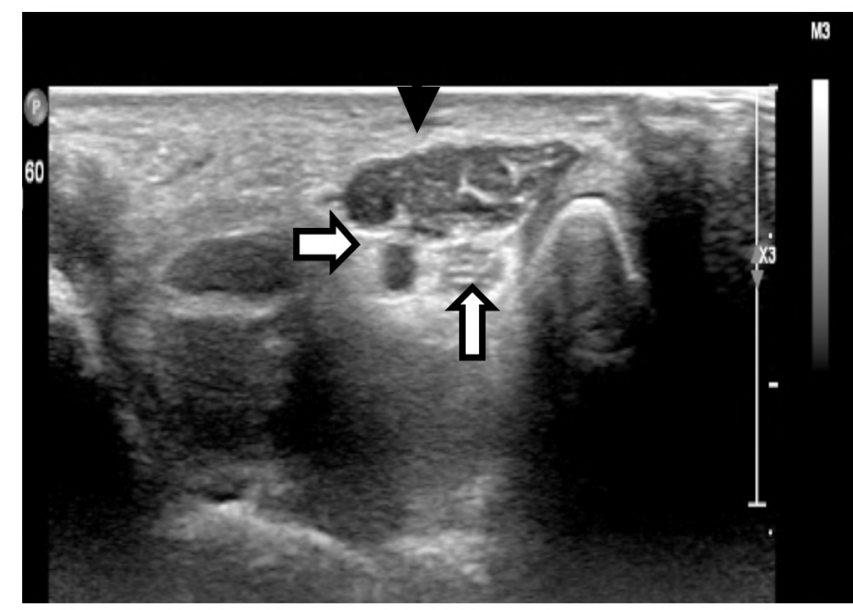

(B)

Fig. (1A,B): 41 years old-female complaining of pain in both wrists with numbness of fingers: (A) MRI axial T1 FS showing a small muscle (black arrow) seen superficial to ulnar nerve and vessles in the Guyon's canal (white arrows), (B) Ultrasound image shows an extra structure in the right tunnel showing muscle echotexture (black arrow) superficial to ulnar nerve and vessles in the Guyon's canal consistent with accessory abductor digiti minimi. 


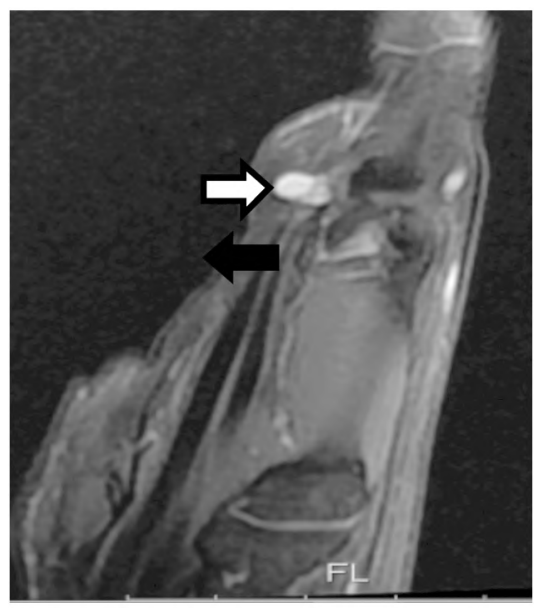

(A)

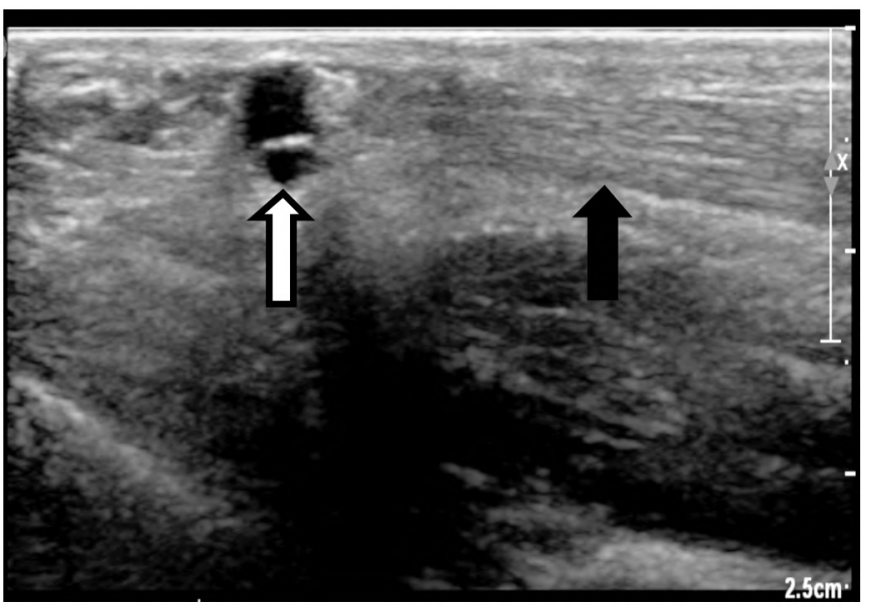

(B)

Fig. (2A,B): 26 years old-female complaining of a lump over the left hand palm between the middle/ring finger: (A) MRI sagittal PD FS showing a small cyst (white arrow) which is seen just medial to the flexor digitorum superficialis tendon (black arrow) at level of head of 3rd metacarpal bone, (B) Ultrasound image of palmar aspect showing small anechoic cyst (white arrow) seen related to flexor digitorum superficialis tendon (black arrow) at level of head of 3rd metacarpal bone consistent with flexor tendon sheath ganglion cyst.
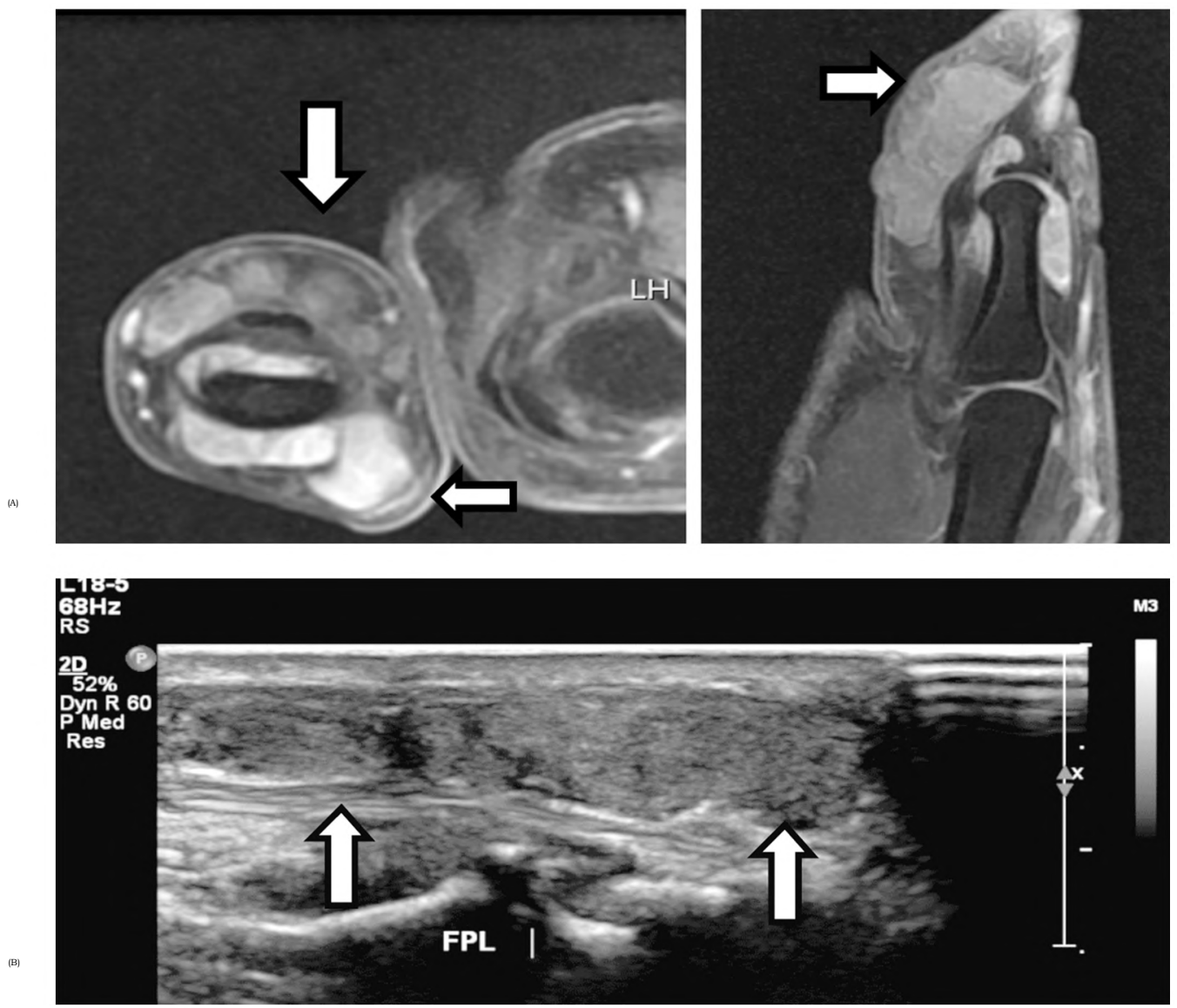

Fig. (3A,B): 25 years old-female complaining of left thumb painful swelling: (A) MRI axial \& sagittal post contrast showing multilobulated mass (white arrows) seen encircling the distal end of proximal and distal phalanx of thumb, partially encasing the flexor and extensor tendons \& showing homogenous enhancement, (B) Ultrasound image shows large multilobulated, homogeneously hypoechoic lesion (white arrows) with large dorsal and volar components and is seen located anterior to and abutting the flexor pollicis longus tendon consistent with Giant cell tumors of flexor pollicis longus tendon. 


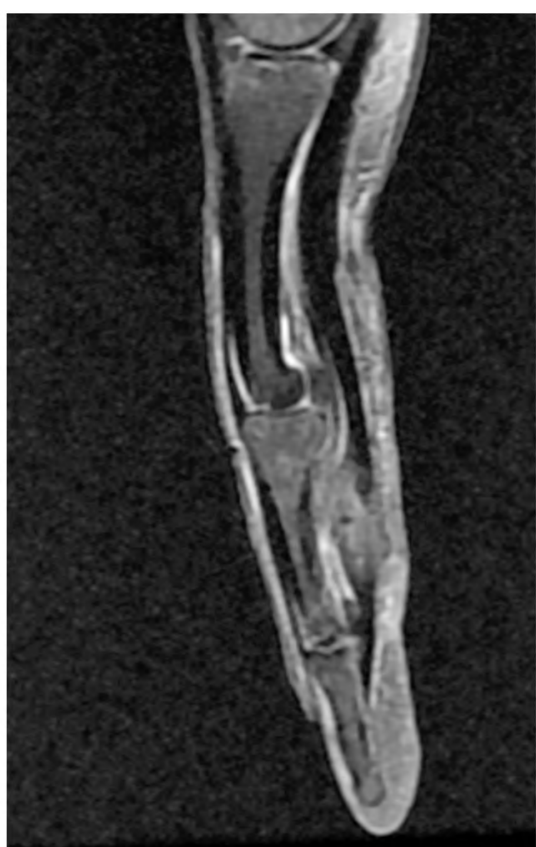

(A)
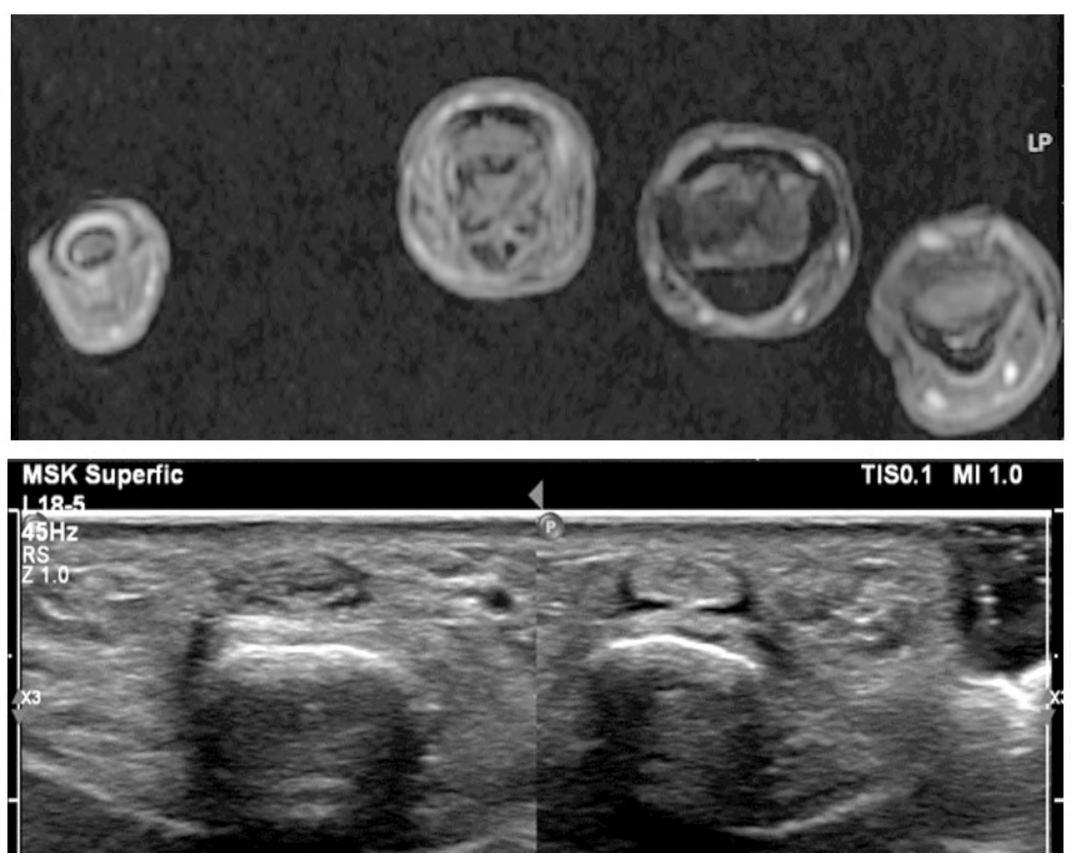

(B)

Fig. (4A,B): 37 years old male complaining of Cut injury of left ring finger (A) MRI axial \& sagittal PD FS: Flexor digitorum profundus tendon shows abnormal increased signals with indistinct fibers; however, the distal attachment site of the tendon appears intact, (B) Ultrasound shows loss of fibrillar pattern noted in the flexor digitorum profundus tendon which appeared relatively thin \& hypoechoic compared to the contralateral tendon. Distal attachment is intact consistent with partial thickness tear of its fibers.

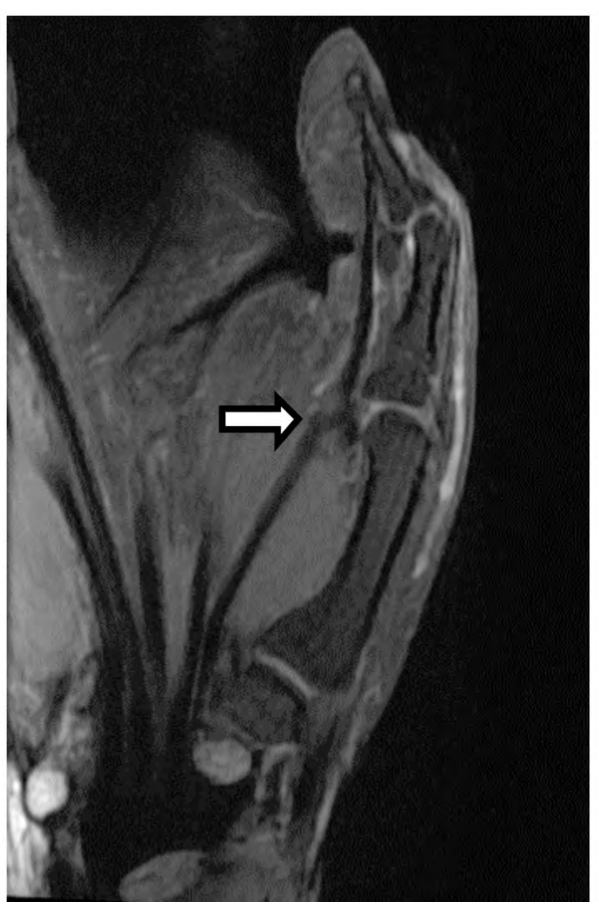

(A)
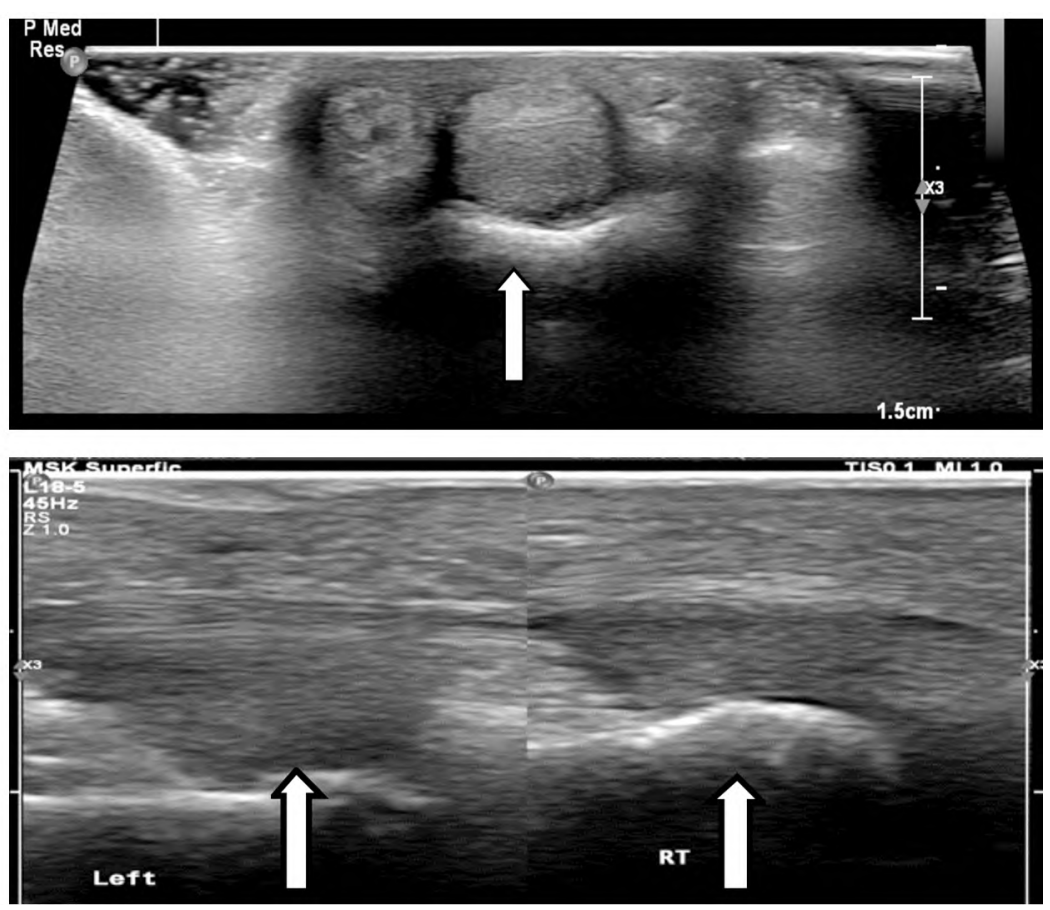

(B)

Fig. (5A,B \& C): 31 years old-female complaining of flexion deformity of her left thumb (A) MRI sagittal PD FS of left thumb: flexor tendon (white short arrow) appears wavy and detached from its normal location close to the proximal phalanx with flexion contraction of terminal pharynx, (B \& C) Ultrasound longitudinal images show increased distance (white long arrows) between the flexor tendon $\&$ the diaphysis of the proximal phalanx of the left thumb compared to the right thumb suggestive of disruption of A1 pulley injury. 

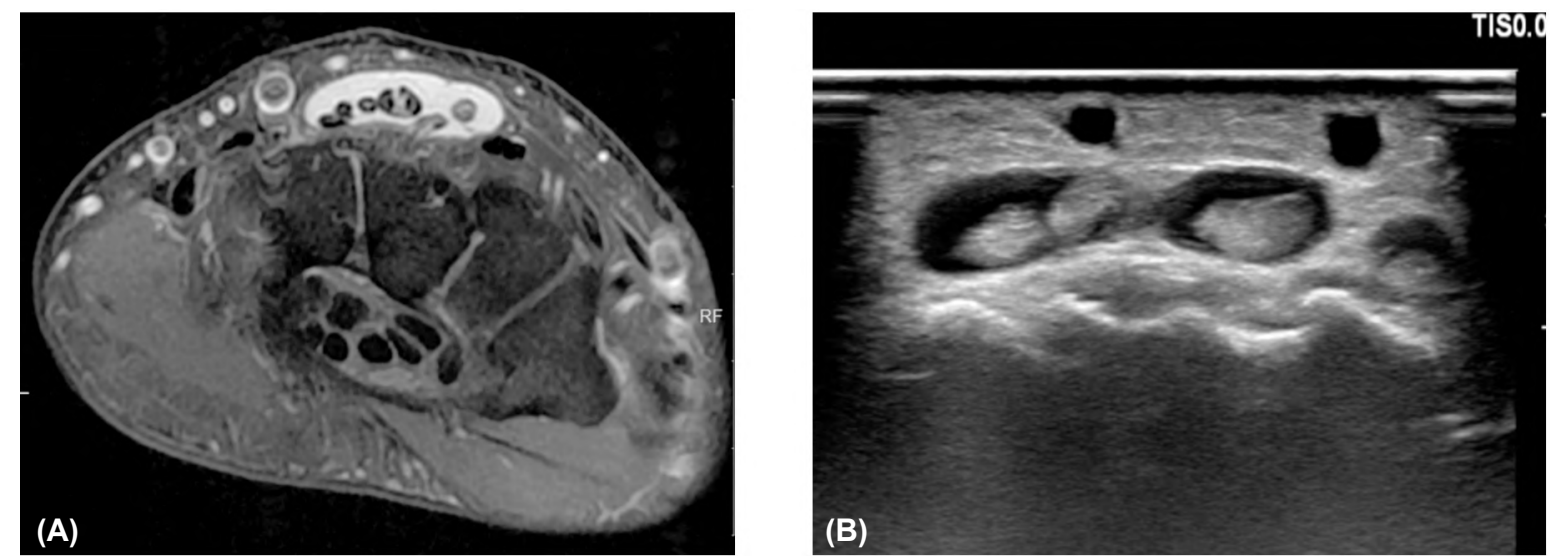

Fig. (6A,B): 31 years old-female complaining of pain in the right wrist joint (A) MRI axial PD FS: Extensor digitorum tendon shows significant amount of peritendinous fluid, (B) Ultrasound shows fluid within the synovial sheath of the extensor digitorum tendon consistent with fourth compartment tenosynovitis.

\section{Discussion}

Ultrasonographic technology has been rapidly advancing over the past few years. The development of high-resolution transducers has increased the potential of ultrasound to evaluate superficial anatomical structures of the hand and fingers. In view of reliability and a good sensitivity: Specificity ratio, ultrasonography has been proposed as the gold standard in assessing tendon involvement [8]

The diagnostic accuracy of ultrasonography allows reasonable decisions to be taken regarding the indications for MRI assessment which can be avoided in a proportion of patients, and also allows better preoperative information of those who do proceed in terms of the likely surgical procedure and aftercare/recovery period, allowing benefits to the patients as well as better allocation of resources, Owing to MRI limited availability and high cost, MRI role became limited despite being the standard practice in the diagnostic assessment of wrist $\&$ hand abnormalities in patients with negative conventional $\mathrm{X}$-ray finding. Therefore, the use of US might represent a feasible alternative [9].

The study was aimed to show the role of ultrasonography as alternative imaging modality in evaluation of tendons abnormalities of the wrist and hand with guiding role for surgical procedures, it included 100 patients with different wrist and hand complaints.

This study was in agreement with multiple comparable comprehensive studies in that ultrasonography is an efficient and accurate imaging method for the evaluation of common tendon abnormalities and its accuracy is equivalent to that of MRI for imaging tendon abnormalities. AlHourani et al., [9] study analyzed a wide-range of injuries and a positive predictive value of $99 \%$ was reported for tendon ruptures, tendonitis, ganglion cysts and soft tissue masses, also El-Deek et al., [8] study described a positive predictive value of $100 \%$ for tendinosis/tenosynovitis, ganglion cysts and solid masses.

Similarly, Hoving et al., [10] found ultrasonography (using a high-frequency probe, $10 \mathrm{MHz}$ ) equivalent to MRI in the detection of tendon sheath disease at the hand and wrist, Also, Stevic and Dodic [11] concluded that ultrasonography is well suited for evaluating tendons. In most cases, its accuracy is at least equivalent to that of MRI for imaging tendon abnormalities. But the advantages of ultrasonography such as accessibility, low cost, dynamic capability, and needle guidance make it as a first-line imaging technique in tendon evaluation.

With regards to tendinosis/tenosynovitis, ultrasonography remained an excellent sufficient imaging modality to assess tendinosis/tenosynovitis, in our study out of 100 patients, 46 patients were diagnosed with tendinosis/tenosynovitis, and it is found that there were equal sensitivity and specificity rates for ultrasound compared to MRI in confirming tendinosis/tenosynovitis (100\% for ultrasound sensitivity and specificity).

In a prospective study by El-Deek et al., [8] out of 50 patients 19 patients were diagnosed with tendinosis/tenosynovitis by ultrasonography same number identified by MRI, the study concluded that ultrasonography was near equal to MRI in the assessment of tendon abnormalities. 
In our study, ultrasonography diagnosed trigger finger associated with tendinosis and tenosynovitis in 4 out of 4 MRI confirmed cases $(100 \%)$ by detecting thickening and hypervascularity of pulley system. Our findings were in agreement with the study done by Vuillemin et al., [12] in that the sonographic signs of stenosing tenosynovitis of the digits have also been well diagnosed as hypoechoic thickening of A1 pulley at level of the metacarpo-phalangeal joint which was a constant finding and may be associated with hypervascularization on color Doppler imaging (91\% of all cases).

With regards to ganglion cyst of tendon sheath our study showed a $96 \%$ sensitivity and $100 \%$ Specificity for ganglion cysts which supported the use of ultrasonography as the first line tool if such a lesion was doubted, In our study, it showed that 16 ganglion cysts out of 17 MRI diagnosed ganglion cysts were correctly diagnosed on ultrasound with only one false-negative which was tiny in size \& deep in location, This is in agreement with the study done by Al-Hourani et al., which demonstrated a $100 \%$ PPV and sensitivity for identifying ganglion cysts by ultrasonography.

Magnetic resonance imaging would be the second imaging modality of choice if dubiety remained, and was considered more accurate in differentiating ganglions from other soft tissue masses including tumors of tendon sheath, arterial aneurysm, arteriovenous malformation, synovitis or even bony lesions. Evaluation of ganglion cysts with non-invasive and simple imaging modality through ultrasonography could invalidate the need for further investigations [13] .

As regards to tendon solid tumors, our study found that the ultrasonography and MRI agreed in $100 \%$ of cases ( 16 out of 16 patients) with solid tumors of tendon sheath; however the ultrasound could not clearly differentiate between giant cell tumor \& fibroma in our study.

In a study done by Lautenbach et al., [13] 84 patients were operated for giant cell tumors of tendon sheath of the hand. The radiographic examinations showed congruent findings regarding size and localization in 84 of 84 cases by ultrasound, 13 of 84 cases by X-ray and 84 of 84 cases by MRI. The study done by El-Deek et al., [14] concluded that ultrasonography is a good modality in the characterization of mass lesion as solid or cystic and assessment of lesion size, internal structure vascularity, and its relation to surrounding structures. MRI imaging helps analyze the tumor matrix by identifying fatty and cystic tissue in a given lesion. MR imaging shows features of aggressiveness and signs of malignancy: Poorly defined margins, invasion into vascular, nervous or osseous structures, peritumoral edema, heterogeneous signal in case of necrosis, and intense enhancement. MR imaging helps discriminate between benign and malignant lesions with a sensitivity of $93 \%$ and a specificity of $82 \%$ [14]

With regards to tendon tear, ultrasonography remained a good imaging modality to assess different types of tears; however evidence in the literature appears scarce on the diagnostic accuracy of ultrasound in identifying tendon tears. Our study found a specificity of $100 \%$ and sensitivity of $88 \%$ for ultrasonography in the diagnosis of tendon injury of the hand and wrist, In our study 24 patients (24\%) had tendon injuries diagnosed by MRI while 21 patients $(21 \%)$ diagnosed by ultrasound.

Of the 24 patients diagnosed with MRI, there were eight patients with complete tears, nine patients with partial-thickness tears, three patients with tendon subluxation without tear and four patients with pulley injury.

Of the nine partial thickness tears confirmed by MRI, ultrasound correctly identified seven cases. In the misdiagnosed two cases, ultrasound described both as normal tendon, while a partial thickness tear was identified at MRI imaging. Of the eight patients MRI confirmed complete thickness tears; ultrasound correctly diagnosed seven patients, only one case was misdiagnosed as partial thickness tear.

Of the three tendon subluxation cases confirmed by MRI, ultrasound correctly diagnosed all the patients, again all four patient of pulley injury could be identified by ultrasound clearly.

Among El-Deek et al., [8] studied cases, ultrasonography diagnosed 10 of 12 cases $(83.3 \%)$ of tendon tear. Discontinuity of the tendons with hematoma in the acute cases were the findings. It published that ultrasonography is powerful for assessment of the tendons with high sensitivity and specificity and over all accuracy in detection of tendon tears.

Akhavan et al., [15] proposed ultrasonography as reliable modality to evaluate tendon injuries in patients with suspicious clinical findings for tendon tear. This research found a specificity of $99.4 \%$ and sensitivity of $100 \%$ for ultrasonography in the diagnosis of tendon rupture in traumas to the volar aspect of the hand and wrist. 
With regards to tendon anatomy variants, no definite comparable study was found, in our study ultrasound showed high PPV and accuracy in detection of different tendon anatomical variant (100\% \& 98\% respectively) with sensitivity \& specificity ( $87 \%$ \& $100 \%$ respectively).

In our study 31 out of 33 patients diagnosed by MRI were correctly diagnosed by ultrasound with only two false-negative (accessory abductor digiti minimi muscle) were missed because of their small sized, the most common variant seen among the patients was accessory abductor digiti minimi muscle, second common variant was Palmaris Longus Variants (which include reversed insertion \& unilateral/bilateral agenesis), Last two variants were less common among the studied group which included proximal origin of the lumbricals \& Extensor Digitorum Brevis Manus.

The major limitation of our study was a relatively large spectrum of tendons anatomical \& pathological abnormalities needed to be covered, so future specific studies with more specific pathology selection are recommended to identify the correlations between ultrasonographic imaging features and MRI examination. Another limitation was a relatively small number of patients, so future studies with a bigger number of patients are suggested.

\section{Conclusion:}

We conclude that the study results show that the role of ultrasound imaging can be expanded in evaluation of different tendon abnormalities with guiding role for surgical procedures and aftercare/ recovery period.

\section{Recommendation:}

We recommend combining clinical evaluation with the use of ultrasonography as a first line imaging modality for (i) evaluating tendon tears $\&$ inflammation and (ii) differentiating ganglion cysts vs. solid swellings in the hand and wrist, and we also feel it is potentially useful in differentiating the pathological nature of soft tissue masses.

Further studies are needed to detect the role of ultrasonography in assessment of other wrist and hand structures as ligament, nerves, vessels and joints.

\section{References}

1- JON A. JACOBSON: Musculoskeletal Ultrasound and MRI: Which Do I Choose? Semin Musculoskelet Radiol., 9 (2): 135-149 DOI: 10.1055/s-2005-872339, 2005.
2- JUSTIN C. LEE and JEREMIAH C. HEALY: Normal Sonographic Anatomy of the Wrist and Hand RadioGraphics, 25: 1577-1590, 2005.

3- FLORENTIN ANANU, MARIUS EUGEN and DRAGOS POPA: Ultrasonography in the diagnosis and management of non-inflammatory conditions of the hand and wrist, Vol. 18, No. 1, 90-95, 2016.

4- NURI KARABAY: US findings in traumatic wrist and hand injuries Diagn. Interv. Radiol., 19: 320-325, 2013.

5- HANAN E. EL HEFNAWY, HOWAYDA F. ZIDAN, SOAD S. EL MOLA, et al.: Correlation between quantitative ultrasonography on small muscles of the foot in diabetic peripheral neuropathy and electrodiagnostic study med. J. Cairo Univ., Vol. 88, No. 5, December: 19751984, 2020.

6- GELLHORN A.C. and CARLSON M.J.: Inter-rater, intrarater, and inter-machine reliability of quantitative ultrasound measurements of the patellar tendon. Ultrasound Med. Biol., 39: 791-6, 2013.

7- HALA I. ELGENDY, HATEM M. ELAZIZI and RASMIA M. ELGOHARY: Ultrasonographic Evaluation of Hand and Wrist Tendons in Patients with Rheumatoid Arthritis. Med. J. Cairo Univ., Vol., 83, No. 2, 2015.

8- AHMED EL-DEEK and ELSAYED DAWOOD: Role of ultrasonography in evaluation of tendons abnormalities in hand and fingers Egyptian Journal of Radiology and Nuclear Medicine, 50: 108, 2019.

9- KHALID AL-HOURANI 1, DAVID GAMBLE 2, PAUL ARMSTRONG, et al.: The Predictive Value of Ultrasound Scanning in Certain Hand and Wrist Conditions J Hand Surg Asian Pac Vol. Mar., 23 (1): 76-81. doi: 10.1142/ S2424835518500108, 2018.

10- HOVING J.L., BUCHBINDER R., HALL S., et al.: A comparison of magnetic resonance imaging, sonography, and radiography of the hand in patients with early rheumatoid arthritis. J. Rheumatol., 31: 663-675, 2004.

11- STEVIC R. and DODIC M.: Ultrasonography of tendon abnormalities. OA Musculoskeletal Medicine, 01; 1 (2): $12,2013$.

12-VUILLEMIN V., GUERINI H., BARD H., et al.: Stenosing tenosynovitis. J. Ultrasound, 15: 20e28, 2012.

13- MARTIN LAUTENBACH, SIMON KIM, MICHAEL MILLROSE, et al.: Nodular giant cell tumour of the tendon sheath of the hand: Analysis of eighty-four casesdiagnostic decisions and outcome, Int. Orthop. Nov., 37 (11): 2211-2215, 2013

14- AHMED EL-DEEK, ELSAYED DAWOOD and AHMED AWAD: Role of ultrasound versus magnetic resonance imaging in evaluation of non-osseous disorders causing wrist pain. Egyptian Journal of Radiology and Nuclear Medicine, 50: 8, 2019.

15- REZA AKHAVAN, EHSAN BOLVARDI, MASOUD PEZESHKI, et al.: Diagnosing Hand and Wrist Tendon Injuries in Patients with Questionable Physical Findings: Let POCUS Show Its True Mettle May Trauma Monthly In Press (In Press), 2019. 


\section{دور الموجات الفوق صوتية والتصوير بالرنين المغناطيسى فى تقييه أوتار الرسخ واليونيد}

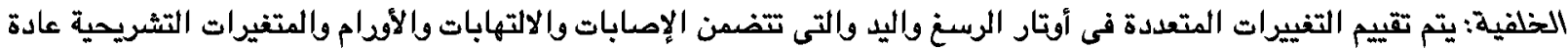

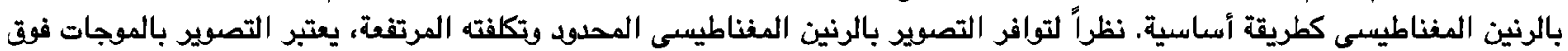

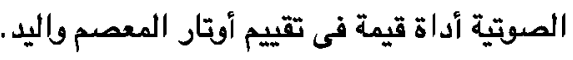

الهدف من الدراسة: تقييم العلاقة بين الموجات فوق الصوتية والتصوير بالرنين المغناطيسى فى تقييم تغييرات أوتار الرسغ اليد المتعددة.

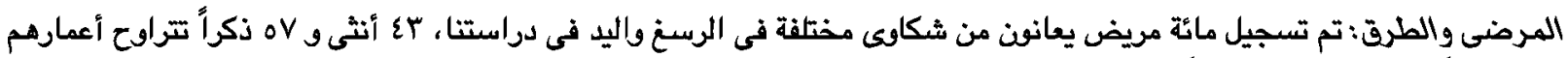

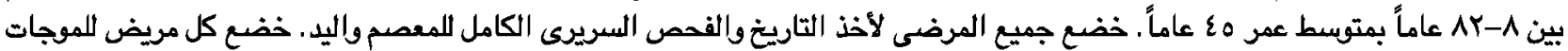
فوق الصوتية أولاً قبل الفحص بالرنين المغناطيسى. عيس.

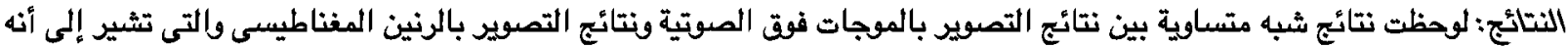

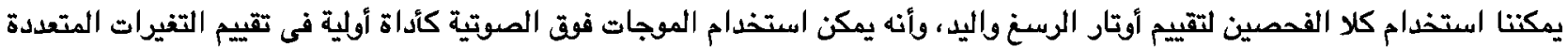

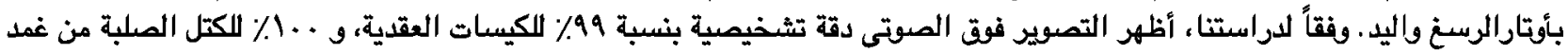

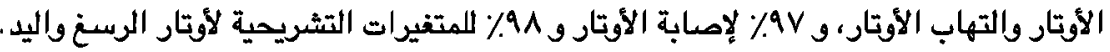

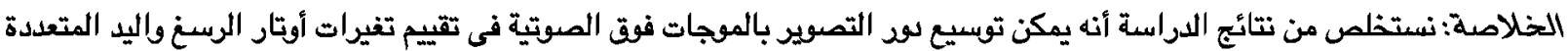

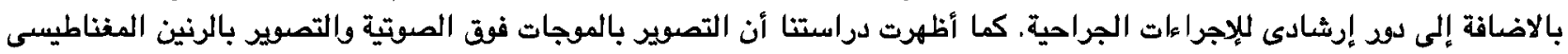

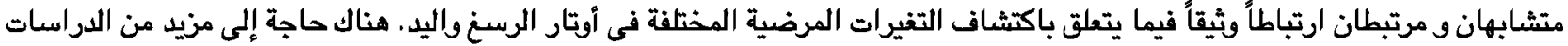

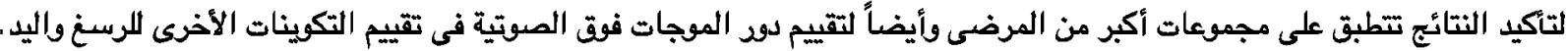

